www.jmscr.igmpublication.org

Impact Factor 5.244

Index Copernicus Value: 83.27

ISSN (e)-2347-176x ISSN (p) 2455-0450

crossref DOI: _http://dx.doi.org/10.18535/jmscr/v4i9.80

\author{
Journal Of Medical Science And Clinical Research \\ IGM Publication \\ An official Publication of IGM Publication
}

\title{
Stiffness a Complication of Total Knee Arthroplasty and Its Management
}

\author{
Authors \\ Shiekh Ajaz, Mohammad Ashraf Khan, Mufti Mahmood, Basit Ahmad, \\ Sajad Jehan, Sawjid Habib
}

\section{Introduction}

Total knee replacement is a highly successful procedure with a success rate of survivorship of 10 to 15 years exceeding $90 \%{ }^{[1,2]}$. However despite advances in the surgical technique and rehabilitation post-operative stiffness continues to be relatively common complication ${ }^{[3-5]}$ Stiffness is defined as an inadequate range of motion (ROM) that results in functional limitations in activities of daily living. Although early studies reported stiffness in $>50 \%$ of patients with TKA,${ }^{[6]}$ the true incidence appears to be $8 \%$ to $12 \%{ }^{[3,7,8]}$. The incidence of complete fibrous ankylosis after TKA is about $0.1 \%$. Biomechanical studies and gait analysis have shown that patients require $67^{\circ}$ of knee flexion during the swing phase of gait, $83^{\circ}$ to ascend stairs, $90^{\circ}$ to $100^{\circ}$ to descend stairs, $93^{\circ}$ to rise from a standard chair, and up to $105^{\circ}$ to rise from a low chair ${ }^{[9,10]}$. There are no universally accepted criteria for diagnosis of stiffness, nor does consensus exist on appropriate timing of intervention. Thorough understanding of the multiple etiologies and available management options can help prevent stiffness in most patients and improve outcomes.

\section{Aims and Objectives}

The study was conducted at the Postgraduate Department of Orthopaedics; Government
Medical College, Srinagar. Aim of the study was to evaluate stiffness a complication of total knee arthroplasty, and its management.

\section{Materials and Methods}

The study was conducted at the Postgraduate Department of Orthopaedics; Government Medical College, Srinagar. After obtaining approval from Hospital Ethics Committee, a written informed consent was taken from the patients for participation in this study. The present prospective study consisted of a total of 25 cases of total knee replacement for symptomatic patients with primary osteoarthritis knee using posterior cruciate ligament substituting implant who were available for follow up. Stiffness was defined as ROM less than 90 degree. Each 8 degrees ROM was given a score of 1 upto the maximum score of 18 [HSS Scoring system] $^{[11]}$

\section{Operative Procedure}

The operations were performed by a single surgeon in one hospital using a uniform surgical approach, instrumentation, technique and release sequence. A medial Para patellar approach was used through a midline skin incision. The length of the incision was identical in all cases with no attempt to perform minimally-invasive surgery. Bone cuts and soft-tissue balancing were done in 
the same sequence. Wound was closed in layers over suction drain

Static quadriceps exercise \& ROM of ankle/ ankle pumps were started on first post-operative day. Suction drain was removed after 24 hours Active and passive ROM of knee were started on 1st post-operative day and toe touch to partial weight bearing was allowed as per tolerance starting the $2^{\text {nd }}$ post-operative day with knee brace

\section{Observation and Results}

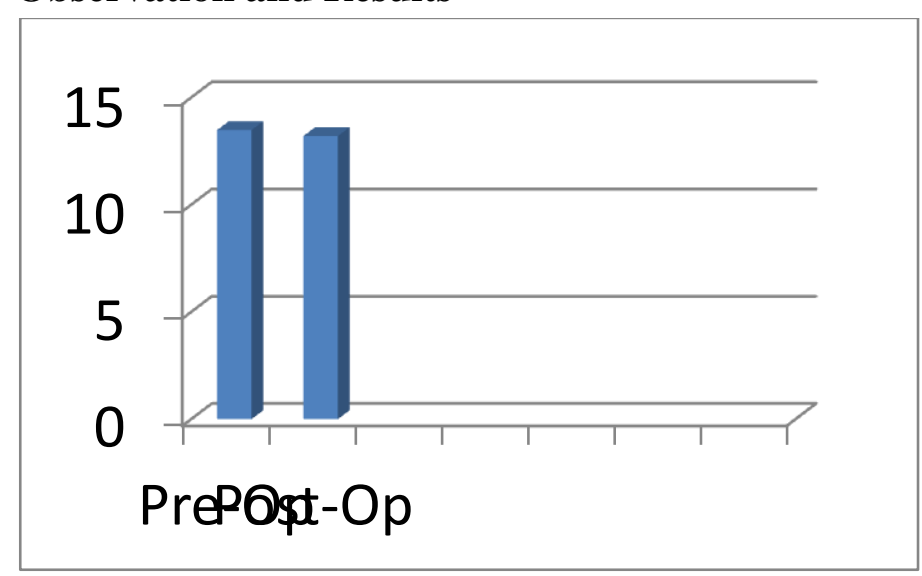

There was no significant difference between pre and post-operative ROM however stiffness was seen in two patients which improved after manipulation under anesthesia.
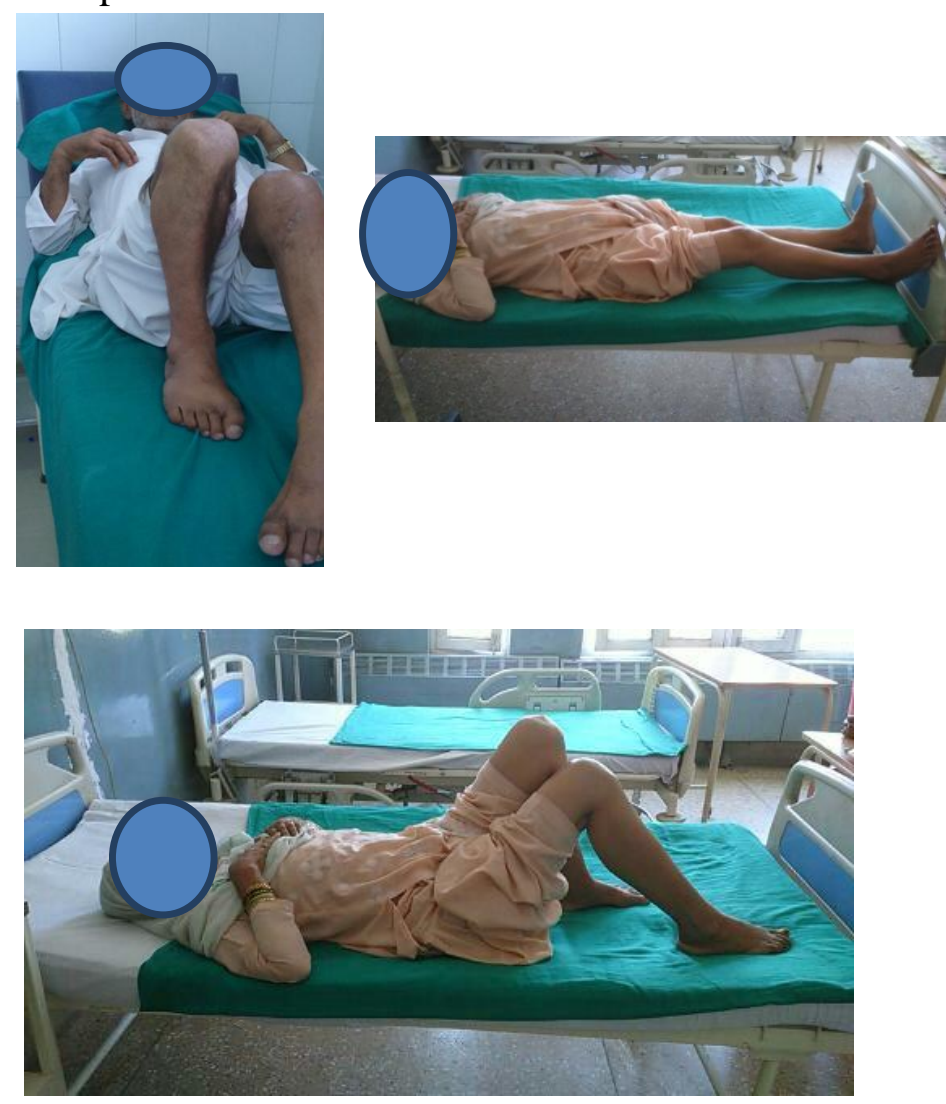

\section{Risk Factors}

Preoperative risk factors include, decreased ROM ${ }^{[5,12]}$, previous surgery around knee ${ }^{[13]}$,obesity. ${ }^{[14]}$. Intraoperative $^{[15-18]}$ risk factors include technical errors which lead to improper flexion-extension gap balancing, malpositioning or over sizing of components, inadequate femoral or tibial resection, excessive joint line elevation, creation of an anterior tibial slope, or incompletely resected posterior osteophytes. Postoperative risk factors include poor patient motivation and compliance, deep infection, arthrofibrosis, patellar complications, complex regional pain syndrome (CRPS), and heterotopic ossification (HO). ${ }^{[19]}$

\section{Management}

Aggressive physical therapy may benefit in patients of persistent stiffness in first 3 months who have no infection or misaligned components Patients with late-onset knee stiffness (ie, >3 months after TKA and after adequate ROM had been achieved initially) also are less likely to benefit from physical therapy. Every effort must be taken to determine the cause of the stiffness. Patients with HO after TKA may benefit from physical therapy and manipulation. Although heterotopic bone has been associated with knee stiffness in some patients, the role and efficacy of excision of $\mathrm{HO}$ about the knee (unlike the hip) are unknown. Patients with limited knee motion secondary to CRPS may benefit from sympathetic blockade and physical therapy. ${ }^{[19] .}$

Treatment includes manipulation, surgical debridement or revision arthroplasty depending upon the cause. There is controversy regarding timing of manipulation, if ROM is less than 90 degree manipulation should be started as early as 10 days $^{[5]}, 2$ weeks $^{[14]}$ or 6 weeks $^{[3]}$ Arthroscopic debridement of adhesions in combination with manipulation has been shown to substantially improve knee ROM in patients with postoperative arthrofibrosis resulting from surgical procedures otherthan $\mathrm{TKA}^{[20-22]}$ However, arthroscopic lysis of adhesions after TKA has not been as successful as lysis after procedures other than $\mathrm{TKA}^{[23,24] \text {. }}$ 
Some authors on the other hand have reported a marked increase in ROM after this procedure [25,26]. In patients with stiffness after TKA secondary to oversized, malpositioned, or loose components, revision arthroplasty is the preferred treatment. ${ }^{[19]}$

\section{Summary}

Stiffness after knee arthroplasty is a known complication it can occur even after adhering to meticulous surgical technique, using appropriate implant and aligning and fixing them properly.

The treatment of stiffness consists of proper pain management and close monitoring. If patients fail to achieve $90^{\circ}$ of flexion by 4 to 6 weeks, aggressive physical therapy should be initiated. If physical therapy fails within 3 months after surgery, closed manipulation should be considered. Arthroscopic or limited open lysis of adhesions can be conducted if the knee is stiff and more than 3 months has lapsed since surgery.

\section{Bibliography}

1. Stern SH, Insall JN: Posterior stabilized prosthesis: Results after follow-up of nine to twelve=years. J Bone Joint SurgAm 1992;74:980986.

2. Ritter MA, Herbst SA, Keating EM, FarisPM, MedingJB: Long-term survival analysis of a posterior cruciate-retaining total condylar total knee arthroplasty. ClinOrthop 1994;309:136145.

3. Scranton PE Jr: Management of knee pain and stiffness after total knee arthroplasty. $J$ Arthroplasty 2001;16:428-435.

4. Esler CN, Lock K, Harper WM, Gregg PJ: Manipulation of total knee replacements: Is the flexion gained retained? J Bone Joint Surg Br 1999;81:27-29.

5. Fox JL, Poss R: The role of manipulation following total knee replacement. J Bone Joint Surg Am 1981;63:357-362.

6. Shoji H, Yoshino S, Komagamine M: Improved range of motion with the Y/S total knee arthroplasty system. ClinOrthop 1987;218:150-163

7. Daluga D, Lombardi AVJr, Mallory TH, Vaughn BK: Knee manipulation following total knee arthroplasty: Analysis of prognostic variables. J Arthroplasty 1991;6:119-128.

8. Mauerhan DR, Mokris JG, Ly A, Kiebzak GM: Relationship between length of stay and manipulation rate after total knee arthroplasty. J Arthroplasty 1998;13:896900.

9. Kettelkamp D: Gait characteristics of the knee: Normal, abnormal, and postreconstruction, in American Academy of Orthopaedic Surgeons Symposium on Reconstructive Surgery of the Knee. St. Louis, MO: CV Mosby, 1978, pp 47-57.

10. Laubenthal KN, Smidt GL, Kettelkamp DB: Aquantitative analysis of knee motion during activities of daily living. PhysTher 1972;52:34-43

11. Weinrauch, N Myers, et al: Comparison of early postoperative rehabilitation outcome following total knee arthroplasty using different surgical approaches and instrumentation. Journal of Orthopaedic Surgery 2006;14(1):47-52

12. Parsley BS, Engh GA, Dwyer KA: Preoperative flexion: Does it influence postoperative flexion after posteriorcruciate- retaining total knee arthroplasty? ClinOrthop 1992;275:204-210.

13. Katz MM, Hungerford DS, KrackowKA, Lennox DW: Results of total knee arthroplasty after failed proximal tibial osteotomy for osteoarthritis. J Bone Joint Surg Am 1987;69:225-233

14. Shoji H, Solomonow M, Yoshino S, D'Ambrosia R, Dabezies E: Factors affecting postoperative flexion in total knee arthroplasty. Orthopedics 1990;13: 643-649.

15. Tanzer M, Miller J: The natural history of flexion contracture in total knee 
arthroplasty: A prospective study. ClinOrthop 1989;248:129-134.

16. Adam C, Eckstein F, Milz S, Schulte E, Becker C, Putz R: The distribution of cartilage thickness in the knee-joints of old-aged individuals-measurement by Amode ultrasound. ClinBiomech (Bristol, Avon) 1998;13:1-10.

17. Figgie HE III, Goldberg VM, Heiple KG, Moller HS III, Gordon NH: The influence of tibial-patellofemoral location on function of the knee in patients with the posterior stabilized condylar knee prosthesis. J Bone Joint Surg Am1986;68:1035-1040.

18. Masri BA, Laskin RS, Windsor RE, Haas SB: Knee closure in total knee replacement: A randomized prospectivetrial. ClinOrthop 1996;331:81-86

19. Matthew R. Bong, MD, and Paul E. Di Cesare, MDJ Am AcadOrthopSurg 2004; 12:164-171

20. Sprague NF III, O’Connor RL, Fox JM: Arthroscopic treatment of postoperative kneefibroarthrosis. Clin Orthop 1982;166: 165-172

21. Del Pizzo W, Fox JM, Friedman MJ, Snyder SJ, Ferkel RD: Operative arthroscopyfor the treatment of arthrofibrosis of the knee. Contemporar Orthopaedics1985;10:67-72

22. Sprague NF III: Motion-limiting arthrofibrosis of the knee: The role of arthroscopic management. Clin Sports Med 1987;6:537-549.

23. Campbell ED Jr: Arthroscopy in total knee replacements. Arthroscopy 1987;3: 31-35

24. Bocell JR, Thorpe CD, Tullos HS: Arthroscopic treatment of symptomatic total knee arthroplasty. Clin Orthop 1991;271:125-134

25. Diduch DR, Scuderi GR, Scott WN, Insall JN, Kelly MA: The efficacy of arthroscopy following total knee replacement. Arthroscopy 1997;13:166-171

26. BaeDK, Lee HK, Cho JH: Arthroscopy of symptomatic total knee replacements. Arthroscopy 1995;11:664-671. 